\title{
Temporal and spatial variation of precipitation in Nansha Islands, South China Sea
}

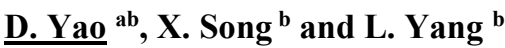 \\ ${ }^{a}$ Sino-Danish College, University of Chinese Academy of Sciences, Beijing 100049, China, ${ }^{b}$ Key Laboratory \\ of Water Cycle and Related Land Surface Processes, Institute of Geographic Sciences and Natural Resources \\ Research, CAS, Beijing 100101, China \\ Email: yaodongxu16@mails.ucas.edu.cn
}

\begin{abstract}
Precipitation is the single natural freshwater source in tropical reefs. In this study, Kriging interpolation, the sequential MK test and other statistical analyses were employed to detect variations in the annual precipitation in the South China Sea (SCS). The annual precipitation in the area ranges from $2000 \mathrm{~mm}$ to $3000 \mathrm{~mm}$. The precipitation in the central area of the reef shows a two-peak pattern oriented NE-SW with a two category spatial distribution. The dendrograms based on between-groups linkage cluster method show the same two groups that HY and YS is one group and CG, DM, NX, ZB and MJ is the other group. Two to four different turning points of annual precipitation were found using MK test, especially relatively large one in 2003 (this was found in all the 7 artificial islands studied here). At the same time, the same trends of the five-year average precipitation were showed in seven islands. Compared with the first five years, the precipitation of the three consecutive five years shows that it is first decreasing, then increasing, and finally decreasing. Annual average precipitation at the next five-year stage in almost all islands is going up larger than the twenty-one-year average precipitation, which is essential for maintaining the reef ecosystem and drinking water for the permanent residents.
\end{abstract}

Keywords: Precipitation, temporal and spatial variation, Mann-Kendall test, tropical reefs 


\section{INTRODUCTION}

Precipitation is the single natural freshwater source in tropical reefs. It is essential for maintaining the reef ecosystem and drinking water for the permanent residents. Therefore, the temporal and spatial characteristics of precipitation have received increasing attention especially in the studies related to climate changes of tropical reefs. In the 20th century, precipitation has changed dramatically in many regions of the world (New et al., 2001). Climate conditions experienced by atoll islands are wide ranging, leading to considerable variability in average annual values of precipitation. For example, in the Western Pacific, the mean rainfall ranges from less than $1000 \mathrm{~mm} / \mathrm{y}$ on Kiritimati (Kiribati) to over $3500 \mathrm{~mm} / \mathrm{y}$ near Funafuti Atoll (Tuvalu) (White and Falkland, 2010).

The South China Sea (SCS) plays a significant role in economic development and provides a wide range of products such as stock of fish and crude oil for humans result from which is the largest semi-closed sea in the western tropical Pacific Ocean, surrounded by several countries, such as Malaysia, Thailand, Vietnam, Brunei, Indonesia, Philippines and China (Ping-Ping Shen et al., 2010). The SCS is one of the most sensitive areas for global climate change in the world (Wenfeng Deng et al.,2019). Therefore, it is important to study the variations of precipitation over long periods, especially in the tropical monsoon climate region of the SCS.

Impact of SST anomalies on winter and summer precipitation in SC has been noted (Jiangnan Li,2018). The characteristics of precipitation diurnal variations in spring and summer are investigated based on the TRMM satellite data from 1998 to 2012. Li Fangzhou et al. (2017) found precipitation decreases after the burst of monsoon, while the major part of this region has positive seasonal difference. However, the present studies is relatively little for the spatial and temporal distribution of precipitation in the vicinity of artificial islands in South China Sea.

Assessing rainfall temporal and spatial variation and any trends by time series analysis in the SCS will provide effective information for managing freshwater resources to improve the restoration and maintenance of its ecology in addition to providing a reference for creating isolines for precipitation and precipitation parameters (e.g., standard deviation and coefficient of variation). The objectives of this study are: (1) to reveal the spatial variations of precipitation in the SCS areas, (2) to identify and decompose the variation patterns of the annual precipitation of 7 reef islands.

\section{MATERIAL AND METHODS}

\subsection{Study area}

The study area is a part of Spratly Islands located in the South China Sea, at approximately $8^{\circ}-12^{\circ} \mathrm{N}$ and $11^{\circ}-$ $117^{\circ} \mathrm{E}$, and covers totally 7 artificial coral islands: Mischief Reef (MJ), Subi Reef (ZB), Fiery Cross Reef (YS), Caurteron Reef (HY), Gaven Reef (NX), Hughes Reef (DM), and Johnson South Reef (CG). The study focus is on the artificial coral islands, where freshwater lenses may exist (Fig. 1) and will herein be referred to as the potential places for human survival and ecological water demand. The Spratly Islands belongs to the tropical marine monsoon climate zone which is characterized by drought season (June-November) and relative rain season (December-May).

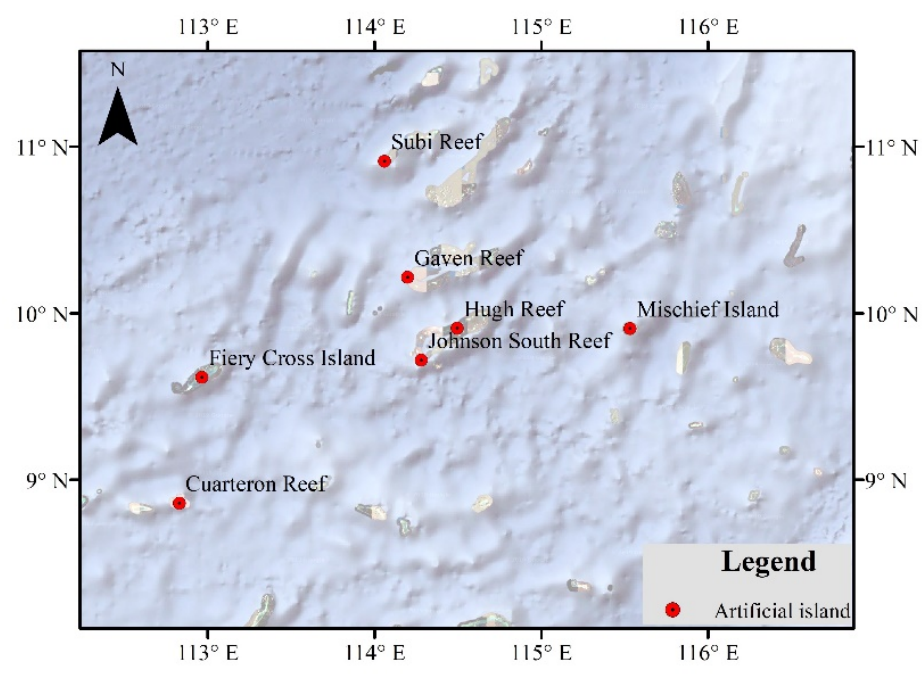

Figure 1. Location map showing artificial islands in the South China Sea (SCS) 


\subsection{Data}

The daily meteorological data(TRMM 3B42 v7 daily precipitation) in the SCS during 1998-2018 were collected from Tropical Rainfall Measuring Mission(TRMM) https://trmm.gsfc.nasa.gov (Huffman,2007). We selected 7 points to represent 7 different islands (Figure 1) and obtained annual meteorological data from the daily meteorological data. The regional average precipitation was obtained by taking the average precipitation value of all points in the area.

\subsection{Method}

In our study, the monthly, and annual precipitation was analysed in the SCS to detect trends during 1998-2018. Firstly, we used the kriging of interpolation gridding methods to reveal the characteristics of the spatial distribution of rainfall. Secondly, we applied the sequential MK test to identify any trends in the original time series. Then, we identified the starting point of abrupt changes and the trend of the original annual precipitation in the 7 islands and the SCS through the sequential MK graph.

\section{Kriging of interpolation methods}

Kriging is a geostatistical procedure that generates an estimated surface from a scattered set of points with zvalues. Kriging assumes that the distance or direction between sample points reflects a spatial correlation that can be used to explain variation in the surface. The Kriging tool fits a mathematical function to a specified number of points, or all points within a specified radius, to determine the output value for each location. Kriging is a multistep process; it includes exploratory statistical analysis of the data, variogram modelling, creating the surface, and exploring a variance surface. We created Kriging of interpolation grid in ArcGIS 10.5 using its spatial analysis toolbox.

\section{Mann-Kendall test}

The Mann-Kendall (MK) nonparametric test can be utilized to characterize precipitation trends for annual, seasonal, and monthly time scales (Kendall, 1975; Mann, 1945).

The test statistic $S$ can be defined in the MK test by (Hirsch and Slack,1984) Eq. (1):

$$
S=\sum_{i=1}^{n-1} \sum_{j=i+1}^{n} \operatorname{sgn}\left(X_{J}-X_{i}\right)
$$

where $\operatorname{sgn}\left(X_{J}-X_{i}\right)$ can be computed by Eq. (2):

$$
\operatorname{sgn}\left(X_{J}-X_{i}\right)=\left\{\begin{array}{c}
+1, \text { if }\left(X_{J}-X_{i}\right)>0 \\
0, \text { if }\left(X_{J}-X_{i}\right)=0 \\
-1, \text { if }\left(X_{J}-X_{i}\right)<0
\end{array}\right.
$$

where $n$ is the length of the series, and $X_{i}$ and $X_{j}$ are the ranked values of the series. For independently and identically distributed data with zero mean, the variance $S_{t}$ of the statistic $S$ is given in Eq. (3) (Nasri and Modarres, 2009):

$$
S_{t}=\left[n(n-1)(2 n+5)-\sum_{p=1}^{q} t_{p}\left(t_{p}-1\right)\left(2 t_{p}+5\right)\right] / 18
$$

where $t_{p}$ is the number of ties for the $p$ value and $q$ is the number of tied values. The MK test statistic $\mathrm{Z}$ can be calculated from Eq. (4) as:

$$
Z=\left\{\begin{array}{c}
(S-1) / \sqrt{S_{t}}, \text { if } S_{t}>0 \\
0, \text { if } S_{t}=0 \\
(S+1) / \sqrt{S_{t}}, \text { if } S_{t}<0
\end{array}\right.
$$

where a $Z$ value outside the interval of \pm 1.96 means that the trend is statistically significant at the $5 \%$ significance level. While the decreasing statistical $Z$ value represents a decreasing trend, the increasing statistical $Z$ value means an increasing trend in the time series. Another index is the slope, which can be regarded as the direction and quantity of the trend, as in Eq. (5):

$$
\text { Slope }=\text { Median }\left[\left(X_{J}-X_{i}\right) /(j-i)\right]
$$

where $1<i<j<n$. Increasing value of slope means it is increasing, a decreasing value means it is decreasing.

To observe any trend changes over time and to detect the start time of any trend, the sequential MK (SQMK) test is applied. The sequential values of the statistic $U F_{k}$ are calculated as follows: 


$$
U F_{k}=\frac{s-E\left(S_{k}\right)}{\sqrt{V\left(S_{k}\right)}}(k=1,2,3, \ldots, n)
$$

Where $U F 1=0 . U B_{k}$ are computed backward from the end of the series $(k=n, n-1, \ldots, 1)$, and $U B 1=0$. The mean and variance of the test statistic area follows:

$$
\begin{aligned}
\mathrm{E}\left(S_{k}\right) & =\frac{n(n+1)}{4} \\
\mathrm{~V}\left(S_{k}\right) & =\frac{n(n-1)(2 n+5)}{72}
\end{aligned}
$$

The intersection points of the values of the $U F_{k}$ and $U B_{k}$ curves represent the approximate turning point of the trend within the time series. The trend turning point is considered significant at the corresponding level (i.e. 1.96 for the $5 \%$ significance level), and neither the progressive nor retrograde curve exceeds certain limits before or after the intersection point.

\section{Statistics and cluster analysis}

Statistical analysis was applied to describe precipitation features and tends such as mean value, maximum value, minimum value etc. While linear equations were generated to predict the precipitation. Cluster analysis method is between-groups linkage cluster. All statistical analyses were performed using SPSS 24.0.

\section{RESULTS AND DISCUSSION}

\subsection{Precipitation annual average distribution}

We used a 21-year (1998 2018) precipitation record based on the daily precipitation from a $0.25^{\circ} \times 0.25^{\circ}$ gridded dataset (TRMM_3B42 v7 daily precipitation) to calculate the annual average and created interpolation grid using kriging to show the distribution in the SCS (Figure 2). The precipitation in the study area ranges mostly from $2000 \mathrm{~mm}$ to $3000 \mathrm{~mm}$. The precipitation in the core area of the reef shows a two-peak pattern of NE-SW direction. It has an obvious double peak spatial distribution consisting of five reefs in Northeast and two reefs in southwest of the SCS, such that the seven islands can be divided into two categories.

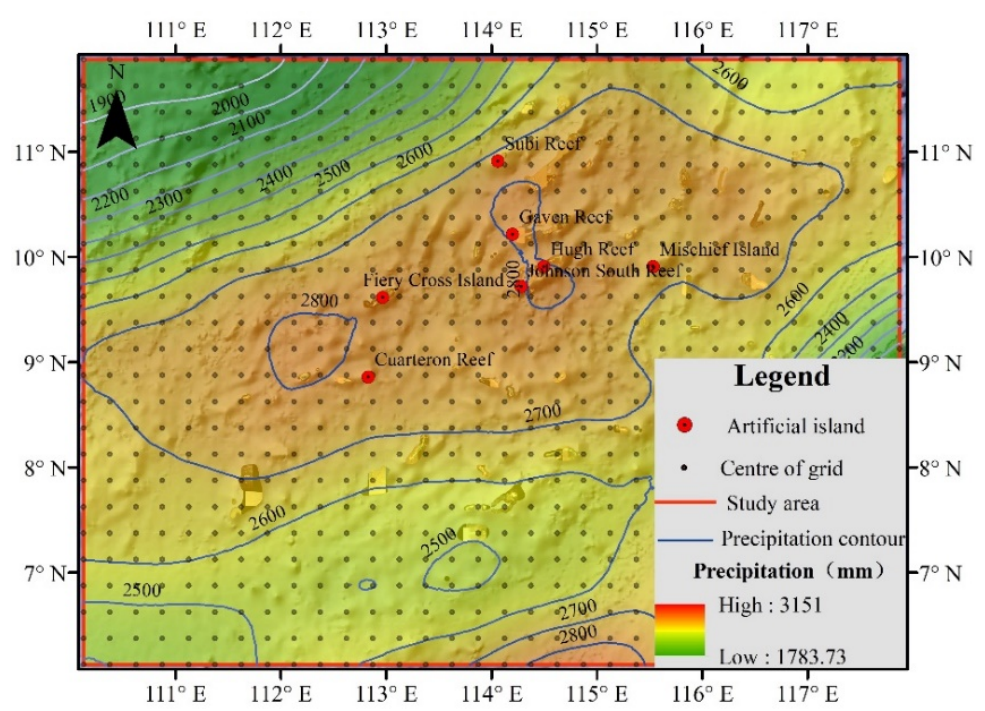

Figure 2. Spatial distribution of annual average precipitation artificial islands in the South China Sea (SCS)

The descriptive statistics of annual precipitation (1998 2018) are shown in Figure 3. The top and bottom lines represent the maximum and minimum values of the data respectively. The maximum of annual precipitation is more than $4200 \mathrm{~mm}$ (ZB, 2013) and the minimum of annual precipitation is less than $1500 \mathrm{~mm}$ (ZB, 2004). The upper and lower lines of the Box-whisker plot are the third quartile and the first quartile respectively. The first quartile ranges from $2335 \mathrm{~mm}$ (HY) to $2555 \mathrm{~mm}(\mathrm{ZB})$ and the third quartile ranges from $3003 \mathrm{~mm}$ (MJ) to $3294 \mathrm{~mm}$ (HY). The thick lines in the middle of the Box-whisker plot show the median of the data, which is ranges from $2628 \mathrm{~mm}(\mathrm{MJ})$ to $2946 \mathrm{~mm}$ (YS). The black solid rectangle in the middle of the Box-whisker plot is mean value. The average annual precipitation in the study area is about $2800 \mathrm{~mm}$ and mean value changes from $2715 \mathrm{~mm}$ (MJ) to $2850 \mathrm{~mm}$ (YS). In addition, the circles at the top and bottom of the Boxwhisker plot mean the extreme values in the sample data, respectively. In 2004, 2015 and 2013, there were 
abnormal precipitation values, indicating that the precipitation in these three years decreased or increased abnormally. The average annual precipitation in the study area is about $2800 \mathrm{~mm}$, the maximum precipitation is over $4200 \mathrm{~mm}$ and the minimum precipitation is less than $1500 \mathrm{~mm}$.

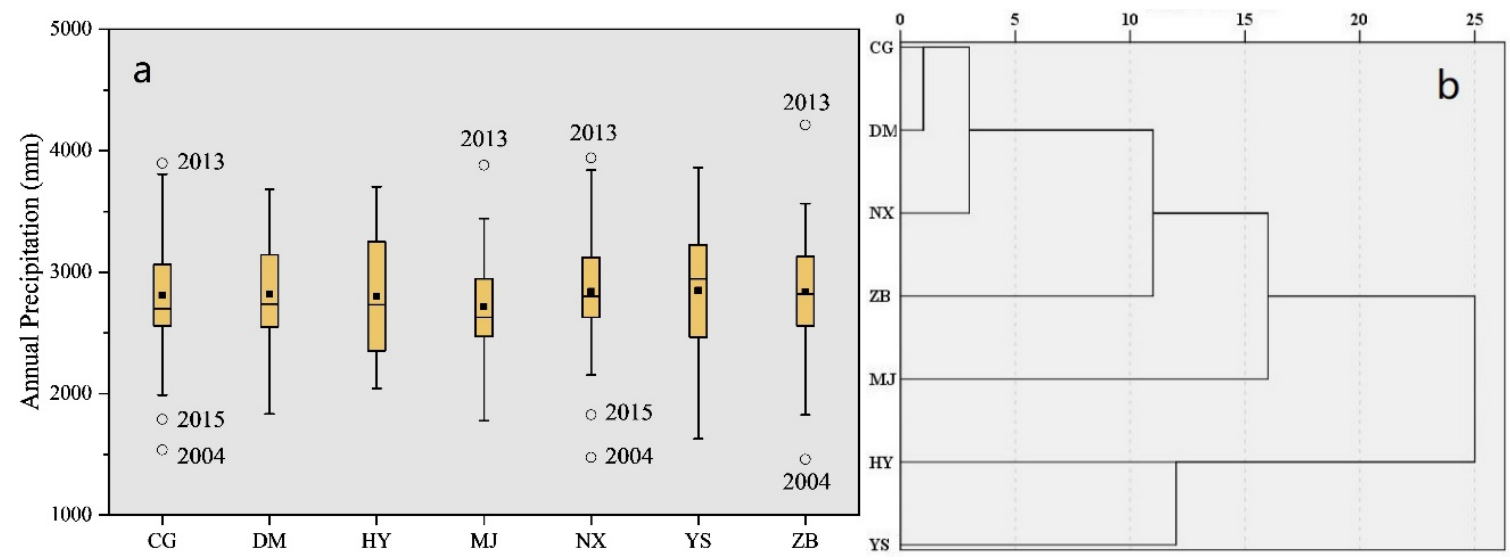

Figure 3. a. Box and whisker plot showing distribution of annual precipitation (1998 2018)

b. Dendrograms based on between-groups linkage cluster method of annual precipitation (1998 2018)

\subsection{Precipitation temporal sequential test statistics}
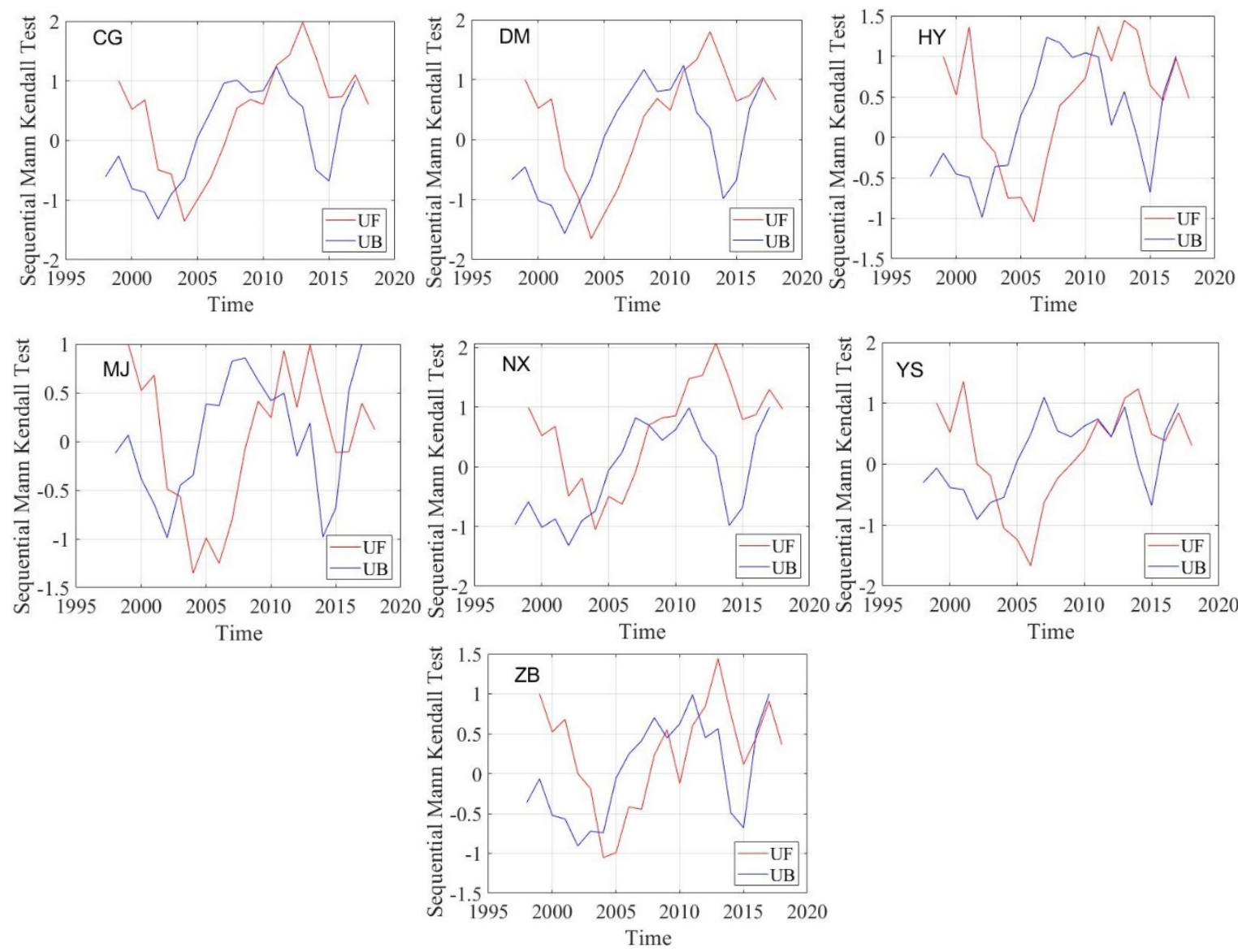

Figure 4. The time series of sequential Mann-Kendall statistics for different islands of annual precipitation in the SCS 1998-2018. The red and blue solid lines represent the original and decomposed series, respectively.

Figure 4 shows the different intersection points of the values of the UF (sequential values of the statistic) and UB (computed backward from the end of the series) curves but the range of UF or UB is between -1.96 to 1.96 such that the trend turning point is considered not significant at the $5 \%$ level, and neither the progressive nor 
retrograde curve exceeds certain limits before or after the intersection point.CG island and DM island have two turning points in 2003 and 2011, NX island has two turning points in 2003 and 2008, HY island has three turning points in 2003,2011 and 2016,MJ has three turning points in 2003,2011 and 2015, ZB island has four turning points in 2003,2009,2011 and 2015,YS island has three turning points in 2003,2012 and 2016.

All the islands have the same change trends in that the increasing trends were observed during 1998 2002 and 2007 2018, while the decreasing trends were found from 2002 2007. To clarify the trend of annual rainfall on islands and reefs can provide support for the prediction of rainfall on islands and reefs and the management of water resources. Consequently, annual average precipitation at the next five-year stage in all islands is going up larger than the twenty-one-year average precipitation.
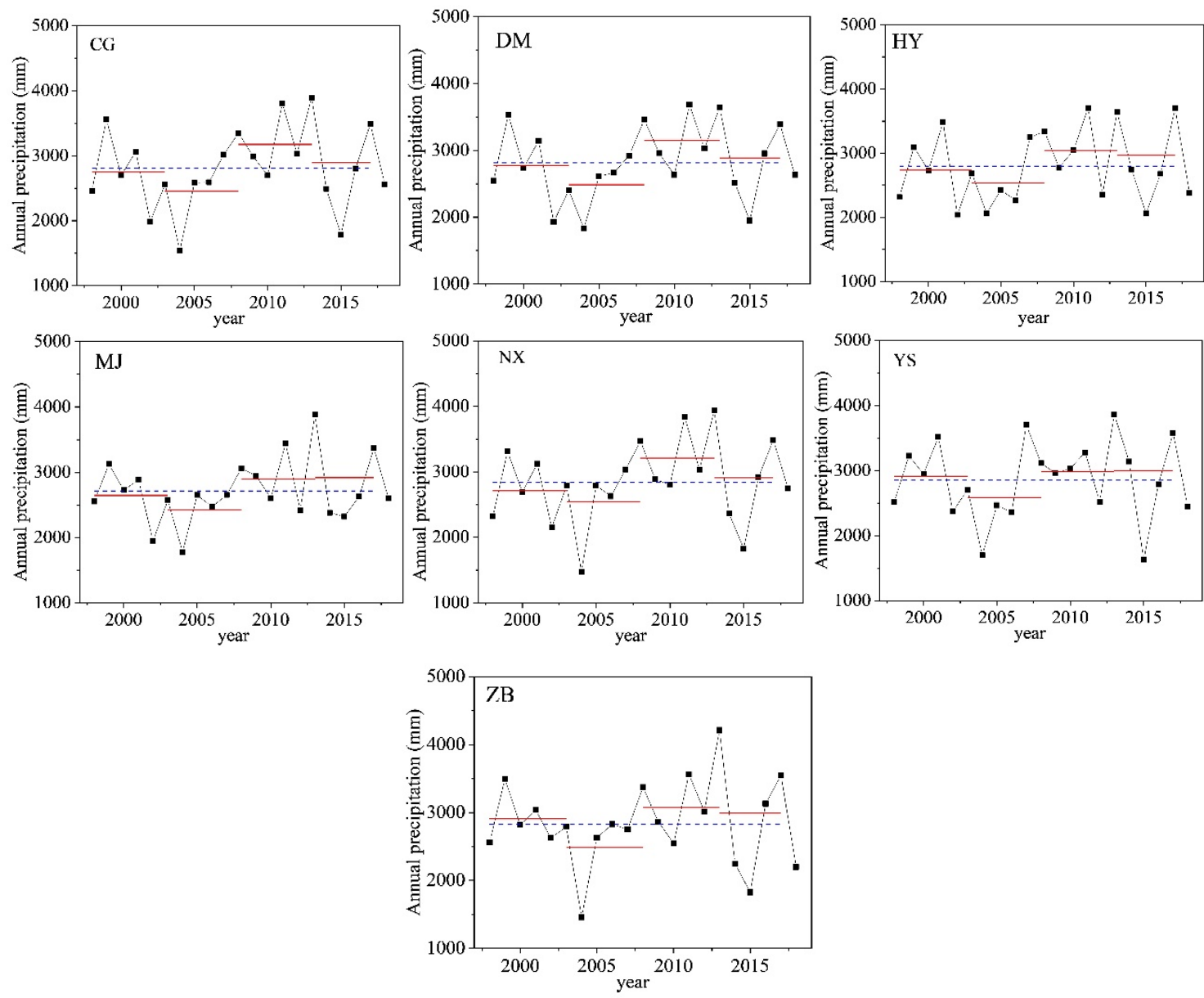

Figure 5. The time series of annual precipitation in different islands in the SCS 1998-2018. The red lines represent the five-year average precipitation, the blue lines represent the twenty-one years average precipitation.

It is well known that secular variation of precipitation is important to understanding regional climate and climate changes. Four stages of variation are found by applying the criteria of five years as one stage. Figure 5 expresses the peculiarity of different stages. Precipitation of the former two five-year stages were less than the twenty-one years average precipitation, while the latter two five-year stages were more than the twenty-one years average precipitation. However, the values of five-year average precipitation are similar to the twentyone-year average precipitation.

\section{CONCLUSION}

This paper described temporal and spatial variation by annual precipitation data. In this study, the kriging interpolation method, the sequential MK test and other statistical analyses were employed to detect variations in the annual precipitation in SCS, China. Using the MK test method, the trends and start time at different islands could be obtained, according to the characteristics of annual precipitation in SCS. At the same time, the trends of the five-year average precipitation were analysed for the seven islands. The major results can be summarized as follows. (1) Statistically no significant increasing or decreasing trends were identified in the original annual precipitation. But the precipitation in SCS has two to four different turning points. (2) The 
precipitation in the study area is between $2000 \sim 3000 \mathrm{~mm}$. The precipitation in the core area of the reef shows a two-peak pattern oriented NE-SW with a two category spatial distribution. The dendrograms based on between-groups linkage cluster method show the same two groups that HY and YS is one group and CG, DM, $\mathrm{NX}, \mathrm{ZB}$ and MJ is the other group. (3) In our study, we found different intersection points of the values of the UF and UB curves but the range of UF or UB is between -1.96 to 1.96 such that the trend turning point is considered not significant at the 5\% level. In addition, neither does the progressive nor retrograde curve exceeds certain limits before or after the intersection point. (4) Precipitation of the former two five-year stages was less than the twenty-one-year average precipitation, while the latter two five-year stages were more than the twentyone-year average precipitation. However, the values of five-year average precipitation are similar to the twentyone-year average precipitation.

\section{ACKNOWLEDGMENTS}

This project is supported by the Strategic Priority Research Program of the Chinese Academy of Sciences, Grant No.XDA13010303. The authors acknowledge contributions from all members of the project team.

\section{REFERENCES}

Ackerley, D., Berry, G., Jakob, C., Reeder, M.J., Schwendike, J. (2014). Summertime precipitation over northern Australia in AMIP simulations from CMIP5.Quarterly Journal of the Royal Meteorological Society, 141(690),1753-1768.

Bombardi, R.J., Carvalho, L.M.V., Jones, C., Reboita, M.S. (2014). Precipitation over eastern south america and the south atlantic sea surface temperature during neutral ENSO periods. Climate Dynamics, 42(5-6), 1553-1568.

Hamed, K.H., Rao, R.A. (1998). A modified Mann-Kendall trend test for autocorrelated data. Journal of Hydrology, 204(1-4), 182-196.

Hirsch, R. M., \& Slack, J. R. (1984). A nonparametric trend test for seasonal data with serial dependence. Water Resources Research, 20(6), 727-732.

Huffman, G. J., R. F. Adler, D. T. Bolvin, G. Gu, E. J. Nelkin, K. P. Bowman, Y. Hong, E. F. Stocker, D. B. Wolff. (2007). The TRMM multi-satellite precipitation analysis: Quasi-global, multi-year, combined-sensor precipitation estimates at fine scale. Journal of Hydrometeorology, 8(1), 38-55.

Jiangnan Li, Dazhen Huang, Fangzhou Li, Zhiping Wen. (2018). Circulation characteristics of EP and CP ENSO and their impacts on precipitation in South China. Journal of Atmospheric and Solar-Terrestrial Physics, 179, 405-415.

Kendall, M.G., 1975. Rank Correlation Measures. 202. Charles Griffin, London.

Li Fangzhou, Li Jiangnan. (2017). Characteristics of diurnal variations of precipitation in spring and summer over the South China Sea and its surrounding areas based on TRMM. Tropical Geography, 37(5),728-737.

Nasri, M., Modarres, R. (2009). Dry spell trend analysis of Isfahan Province, Iran. Int. J. Climatol.,29, 14301438.

New, M., Todd, M., Hulme, M., Jones, P. (2001). Precipitation measurements and trends in the twentieth century. Int. J. Climatol.,21, 1899-1922.

Ping-Ping Shen, Ye-Hui Tan, Liang-Min Huang, Jian-Lin Zhang, Jian-Qiang Yin. (2010). Occurrence of brackish water phytoplankton species at a closed coral reef in Nansha Islands, South China Sea. J. Marine Pollution Bulletin, 60(10), 1718-1725.

Rauscher, S.A., Coppola, E., Piani, C., Giorgi, F. (2010). Resolution effects on regional climate model simulations of seasonal precipitation over Europe. Climate Dynamics, 35 (4),685-711.

Rodriguez-Puebla, C., Encinas, A.H., Nieto, S., Garmendia, J. (998). Spatial and temporal patterns of annual precipitation variability over the Iberian Peninsula. Int. J.Climatol., 18, 299-316.

Wenfeng Deng, Gangjian Wei, Jian-xin Zhao, Ti Zeng. (2019). Anthropogenic effects on tropical oceanic climate change and variability: An insight from the South China Sea over the past 2000 years. Quaternary Science Reviews,206,56-64.

White. I., Falkland. T. (2010). Management of freshwater lenses on small Pacific islands. Hydrogeol. $J ., 18(1), 227-246$

Yang, P., Xia, J., Zhang, Y.Y., Hong, S., 2017. Temporal and spatial variations of precipitation in Northwest China during 1960-2013. Atmos. Res. ,183, 283-295.

Yao, T., Thompson, L., Yang, W., 2012. Different glacier status with atmospheric circulations in Tibetan Plateau and surroundings. Nat. Climate Change, 1580, 1-5.

Zhang, Q., Li, J., Singh, V.P., Xiao, M., 2013. Spatio-temporal relations between temperature and precipitation regimes: Implications for temperature-induced changes in the hydrological cycle. Glob. Planet. Chang. ,111, $57-76$. 